\title{
Diversity Influences Tree Aboveground Carbon Stocks Through Functional Diversity and Functional Dominance in the Dry Evergreen Afromontane Forest of Hararghe Highland, Southeast Ethiopia
}

Mengistu Teshome ( $\nabla$ menguteshe2012@gmail.com )

Oda Bultum University https://orcid.org/0000-0002-6447-2651

Zebene Asfaw

Wondo Genet College of Forestry and Natural Resources

Muktar Mohammed

Oda Bultum University

\section{Research}

Keywords: community weight mean, mixed effect model, niche complementarity, selection effect, structural equation modeling

Posted Date: August 11th, 2020

DOI: https://doi.org/10.21203/rs.3.rs-53977/v1

License: (c) (i) This work is licensed under a Creative Commons Attribution 4.0 International License.

Read Full License 


\section{Abstract}

Background: The relationship between biodiversity and ecosystem function has increasingly been debated as the key ecological issues behind ecosystem service provision. Still, many experimental and theoritical based studies have reported inconsistent patterns of biodiversity and ecosystem function relationships, supporting either niche complementarity or selection effect hypothesis. In this study, aboveground carbon (AGC) stock used as a proxy for ecosystem function and examined its relationship with species diversity, through functional diversity and functional dominance. It is hypothesized that (i) diversity influences AGC through functional diversity and functional dominance effects; and (ii) effects of diversity on AGC would be parted for both functional dominance and functional diversity. Community weight mean (CWM) of functional traits (wood density, specific leaf area, and maximum plant height) was calculated to assess functional dominance (selection effects). As for functional diversity (complementarity effects), multi-trait functional diversity (selection effects) indices were computed. The first hypothesis was tested using structural equation modeling. For the second hypothesis, the effects of environmental variables such as slope, aspect and elevation were tested first, and separate linear mixed effects models were fitted afterward for functional diversity, functional dominance, and both.

Results: Results revealed that tree aboveground carbon varied significantly along the slope gradient. Species diversity (richness) had a positive relationship with aboveground carbon, even when elevation effects were considered. As predicted, diversity effects on aboveground carbon were mediated through functional diversity and functional dominance, suggesting that both the niche complementarity and the selection effects are not exclusively affecting carbon stock. However, the effects were greater for functional diversity than for functional dominance. Furthermore, functional dominance effects were strongly transmitted by CWM of maximum plant height, reflecting the importance of forest vertical stratification of diversity and carbon relationship. We therefore argue for stronger complementary effects that would be induced also by complementary light use efficiency of tree and species growing in the understory layer.

Conclusions: Species diversity (richness) influences carbon stock through functional diversity and functional dominance. Both the niche complementarity and selection hypotheses are important predictors of carbon stock in the study forest.

\section{Background}

One of the main ecological issues is the relationship between plant diversity and the functioning of the ecosystems (Ruiz-Jaen and Potvin 2011; Cavanaugh et al. 2014), and some aspects of climate related effects have been well tested (Durán et al. 2015; Porter et al. 2015; Wu et al. 2015). Because biomass is an important component of forest stand productivity, it is also possible to link the relationship between biomass carbon and plant diversity to the biodiversity component and ecosystem function (Lasky et al. 2014; Mensah et al. 2016). Hence, a clear understanding of how diversity and dominance affect ecosystem function is important not only in theory-based forest management, but would also help direct 
strategies for the conservation and restoration of threatened or fragile forest ecosystems (Cavanaugh et al. 2014; Ruiz-Jaen and Potvin 2010; Mensah et al. 2016).

The niche complementarity and selection effect hypotheses (Tilman et al. 1997; Grime 1998) are the two newly proposed ecological hypotheses commonly used to elucidate the role of plant diversity in ecosystem dynamics, processes and functions. The selection effect hypothesis postulates that a higher probability of occurrence of dominant species or traits (as a result of competition) would influence the functioning of the ecosystem in a diverse group of species (Grime 1998). The niche complementary effect hypothesis states that increasing diversity would promote a wider range of functional traits and provide opportunities for species to use the available resources efficiently, thereby increasing ecosystem function and less competition (Tilman et al. 1997). The niche complementary hypothesis is usually inferred when explaining higher production of biomass and productivity in highly diverse ecosystems (Mensah et al. 2016). Higher biomass, however, may also result from dominant species with strong resource responses and/or strong ecosystem impacts that refers to selection effects (Reich et al. 2001).

The relationship between diversity and ecosystem function (productivity) is inconsistent in whether these are positive, negative or no relationship. For instance, Li et al. (2018) reported the positive relationship species richness and above ground biomass in a primary Pinus kesiya forest of Yunnan, southwestern China. Porter et al. (2015) observed a positive relationship between species richness and above ground biomass across tropical forest biomes. Zhang and Chen (2007) in a natural temperate spruce and pine forest, found a positive correlation between diversity and aboveground biomass. In contrary, Jerzy and Anna (2015) have reported a negative relationship between species diversity and biomass storage in a pine forest in Europe, while other studies have found no or negative relation between aboveground biomass (AGB) and tree species diversity in forest ecosystems (Whittaker and Heegaard 2003).

The relationship between the component of biodiversity and the function of the ecosystem (productivity) is incoherent in whether these relationships are positive, negative or not. For example, in a primary Pinus kesiya forest of Yunnan, southwest China, Li et al. (2018) reported the positive relationship species richness and above-ground biomass. Porter et al. (2015) found a positive relationship between species diversity and aboveground biomass in tropical forest biomass. Zhang and Chen (2007) found a strong association between diversity and aboveground biomass within a natural temperate spruce and pine forest. In contrary, Jerzy and Anna (2015) recorded a negative relationship between species diversity and the storage of biomass in a European pine forest, while other studies have found no relation between aboveground biomass (AGB) and tree species diversity in forest ecosystems (Whittaker and Heegaard 2003).

Complementarity and selection are two important mechanisms used to explain the role of species diversity in ecosystem functioning (Diáz and Cabido 2001; Tilman et al. 1997). A variety of functional traits (functional diversity) among species are assumed to mainly reflect the complementarity effect, and the traits of dominant species (functional dominance) are assumed to mainly reflect the selection effect (Mensah et al. 2016). Effects of functional diversity and functional dominance on ecosystem functioning 
have received increasing attention recently (Baraloto et al. 2012; Clark et al. 2012; Ruiz-Jaen and Potvin 2011; Song et al. 2014). some recent forest ecosystem studies support the selection effect hypothesis (Lin et al. 2016; Prado-junior et al. 2016), while others support the complementarity of niches more (Morin et al. 2011; Wang et al. 2011; Mensah et al. 2016). Moreover, Grime (1998) proposed that functional dominance played a more important role in ecosystem functioning when species differed substantially in their abundances. Several scholars have argued that both hypotheses are not mutually exclusive and could potentially determine the effects of diversity on ecosystem functions (Cavanaugh et al. 2014; Lasky et al. 2014), and especially through competitive exclusion (selection effects) and complementary use of resources by competitors (Porter et al. 2015; Mensah et al. 2016; Mensah et al. 2018). Understanding whether diversity influences on ecosystem function are more likely mediated through functional diversity than functional dominance, or vice versa, will bring substantial insights into which mechanism is more relevant.

Few studies have addressed the relationships between diversity and ecosystem function in natural dry evergreen Afromontane tropical forests. Using aboveground tree carbon data in a dry evergreen Afromontane forest in Southeast Ethiopia, we examined the relationship between diversity and aboveground carbon stocks through the effects of functional diversity and functional dominance. We hypothesized that (i) diversity influences tree aboveground carbon stock through both functional diversity and functional dominance effects. However, there are notions that diversity and carbon relationships can be caused by covarying environmental factors (Cavanaugh et al. 2014; Ouyang et al. 2016). Therefore, altitude, slope and aspect were considered as the most environmental factor in this forest and tested for their influences on tree aboveground carbon stocks. In addition, while accounting for significant environmental factors effects, we also hypothesized that (ii) effect of the diversity of tree aboveground carbon stock would be parted for both functional dominance and functional diversity.

\section{Materials And Methods}

\section{Study area}

The study was conducted in the Dindin dry evergreen Afromontane forest in the Hararghe highlands of southeast Ethiopia. The geographical location of the study site lies between $40^{\circ} 10^{\prime} 40^{\prime \prime}$ to $40^{\circ} 18^{\prime} 50^{\prime \prime} \mathrm{E}$ and $8^{\circ} 33^{\prime} 0^{\prime \prime}$ to $8^{\circ} 40^{\prime} 40^{\prime \prime} \mathrm{N}$ with elevation ranges between 2,124 and $3,069 \mathrm{~m}$ a.s.l. and situated around $336 \mathrm{~km}$ southeast of Addis Ababa (Fig.1). Due to the lack of long term climatic data for the study site, the climate estimator software tool, New LocClim (fao 2005; Grieser et al. 2006) was used to produce long term monthly rainfall and temperature data for the study site. The mean annual temperature (MAT) and mean annual precipitation (MAP) at study site was estimated to be $25.6^{\circ} \mathrm{C}$ and $804 \mathrm{~mm} /$ year, respectively. Precipitation at study site has a bimodal distribution pattern with a long rainy season lasting from June to October and a short rainy season from April to May (Fig. 2). The soils of study area developed for a wide range of parent materials, including volcanic and mixed limestone and sandstone over a Precambrian basement. Leptosols are most abundant soil types which classified as Haplic and Lithic leptosols. Lithic leptosols covers are most extensive on high in mountainous relief hills and parallel 
ridges and river gorges having very steep slopes (30-60\%) (Tefera et al.1996; Elias 2016). According to Friis et al. (2010), the vegetation type in the study area can be categorized as Tropical dry evergreen Afromontane forest, which characterized by a dry climate. Woody species such as Afrocarpus falcatus, Maesa lanceolata, Allophylus abyssinicus and Vernonia myriantha are a dominant species.

\section{Vegetation data collection}

A stratified systematic sampling of 54 plots separated by $200 \mathrm{~m}$ in elevation raise $(2300 \mathrm{~m}$ a.s.l., $2500 \mathrm{~m}$ a.s.l., 2700, and $2900 \mathrm{~m}$ a.s.l.) were established at $200 \mathrm{~m}$ intervals along the four horizontal transects, which initial plot was selected randomly. This approach was adopted for two main reasons: (i) there is a minimum sampling bias as all woody species in the study forest are represented; (ii) the effect of area (the decrease in area from bottom to top of a mountain) is minimized, as all forest areas are included. Moreover, this procedure gives a precise indication of species represented and used to achieve better documentation of changes in species distribution patterns along an elevation gradient (Aynekulu et al. 2012; Arellano et al. 2016). The plot size of $20 \mathrm{~m}$ x $20 \mathrm{~m}$ was used to record trees species. In each plot, height, diameter at breast height (D) and individual abundance of each individual species were recorded. For the purpose of this study, trees are one stemmed woody plants with heights $\geq 5 \mathrm{~m}$. The name of the species was identified in the field whenever possible, but in doubtful cases vouchers were collected and pressed for further identification and confirmation at the Addis Ababa University herbarium.

Environmental variables such as elevation, slope, aspect and geographical location of each plot were recorded. The elevation was measured by using a GPS garmin; whereas, the slope and aspect were measured by using a compass meter.

\section{Estimation of aboveground biomass carbon}

A recent allometric equation developed by Chave et al. (2014) is unique allometric equations which apply in all ecosystems, because this equation encompasses important parameters like diameter, height and wood density. Thus, allometric equation developed by Chave et al. (2014) was used to estimate the above ground biomass as given below:

\section{$\operatorname{AGB}(\mathrm{kg})=0.0673 x\left(\rho D^{2} \mathrm{H}\right)^{0.976}$}

Where AGB is the aboveground biomass of trees $(\mathrm{kg}), \rho$ is the specific wood density $\left(\mathrm{g} \mathrm{cm}^{-3}\right), D$ is the stem diameter at breast height $(\mathrm{cm})$, and $\mathrm{H}$ is the total height of trees $(\mathrm{m})$.

Aboveground biomass carbon was determined by assuming 47\% of AGB containing carbon (IPCC 2006). The total AGB carbon for each plot, were calculated by summing up AGB carbon for all species. Carbon stocks were determined for each plot and then extrapolated to tonnes per hectare.

\section{Functional diversity and dominance metrics}


Taxonomic diversity was used to measure diversity, at each plot. Species richness was used to characterize the taxonomic diversity (Magurran 2004). Species richness at plot level referring to the number of different species counted in each plot. To quantify functional diversity and functional dominance, three functional traits that are relevant to the ecosystem function of interest (i.e., biomass and carbon storage) were considered, because carbon storage is strongly dependent on wood and foliage structures, in this study, therefore, traits such as wood density (WD), specific leaf area (SLA), and maximum plant height (PHm) was considered. Data on wood density were extracted from the Global Wood Density Database (Zanne et al. 2009). In case multiple values were available for a single species, the average wood density was used. SLA and PHm were extracted from the TRY database (Kattge et al. 2011; Maire et al. 2015). When the data for a particular species was missing, the average genus wood density and SLA were used.

Functional diversity metrics, functional richness (FRic), functional evenness (FEve), functional divergence (FDiv), and functional dispersion (FDis) at each plot (Cavanaugh et al. 2014; Zhang et al. 2014; Finegan et al. 2015; Villégeret et al. 2008) were estimated, using the values of the functional traits by "FDiversity" software (Cavanaugh et al. 2011 2012). These diversity indices are multi-trait based functional diversity metrics that includes both the relative weight of each species and the pairwise functional difference between species.

Functional dominance was quantified by estimating the plot level community weight mean (CWM) for each functional traits. CWM is the mean of each species trait value weighted by the relative abundance of that species (Cavanaugh et al. 2014). The CWM for WD, SLA, and PHm was estimated at each plot, again using the diversity software (Cavanaugh et al. 2011).

\section{Statistical analysis}

\section{Structural equation modeling}

Structural equation modeling (SEM) is a powerful, multivariate statistical model found increasingly in ecological studies to test and evaluate multivariate causal relationships. SEMs differ from other modeling techniques as they test the direct and indirect effects on presupposed causal relationships (Fan et al. 2016). This is particularly important, as we hypothesized that the diversity effects would be mediated through both functional diversity and functional dominance. Therefore, we tested the indirect and direct effects of diversity (species richness) on aboveground carbon. Two separate structural equation models were specified representing (a) full mediation: postulate that diversity effects are fully mediated by functional diversity and dominance metrics; and (b) partial mediation: present that there are both direct and indirect diversity effects through functional diversity and functional dominance metrics on aboveground carbon. Due to the presence of multiple measures of functional diversity and functional dominance, stepwise selection techniques were used to select the most relevant functional diversity and functional dominance metrics for the above ground carbon data. 
The overall fit of the SEMs model was evaluated using Goodness of fit index (GFI), value should be close to 0.95 or higher (Hu and Bentler 1999), Chi-square (X2) and standardized root mean residual (SRMR $\leq$ 0.080). The standardized coefficients were used to make direct comparisons across paths (Grace and Bollen 2005). SEMs were fitted in the R statistical software package, using the "sem" function in "lavaan" package and latter, output graph was visualized by using "semPlot" package again in R.

\section{Linear mixed effects models}

Linear mixed-effects models (LMMs) are an important part of statistical models that can be used to analyze correlated data (Galecki and Burzykowski 2013). Prior to the mixed-effects modeling, the significant environmental factors and species richness effects on aboveground carbon stock were tested. Environmental factors are expected to have effects on plant composition, growth, and survival (Mensah et al. 2016; Zhang et al. 2014) and for this reason for standing aboveground biomass and carbon stocks. Here, the focus was given to the factors that are determinant and quantifiable in the area, that is, topography (elevation, slope and aspect) (Geldenhuys 2002). The effects of elevation, slope and aspect of aboveground carbon stock were tested using simple linear models in R. In case, these variables showed no significant effect on the carbon stock and further analyses was performed and multiple linear regressions were used to test their effects on aboveground carbon storage. For both simple and multiple linear models, Shapiro-Wilk tests $(W=0.985, p$-value $=0.739)$ were used to check for the normality of the square root transformed aboveground carbon data and of the residuals. Further, Breusch-Pagan tests, value inflation factor (VIF) and Durbin-Watson statistics were used to test for heteroskedasticity, multicolinearity and autocorrelation between residuals, respectively. The effect of each diversity component (i.e., functional diversity and functional dominance) on carbon storage was evaluated by fitting separate linear mixed-effects models (Zuur et al. 2009). Elevation was considered as random factors and each measure of functional diversity (i.e., FRic, FEve, FDiv, and FDis) and functional dominance (i.e., CWM of WD, SLA, and PHm) as fixed effects. Next, mixed effects models were fitted to evaluate the individual effect of each functional diversity and functional dominance metric; the combined effects of functional diversity metrics; the combined effects of functional dominance metrics; and combined effects of functional diversity and functional dominance metrics. Further, the effect of each diversity component (fixed effects) on above ground carbon storage was determined using a mixed effects model (Bates et al. 2015) with 'Type III analysis of variance with Satterthwaite's method'. To run mixed effects model package 'Ime4' (Bates et al. 2015) was used in R and variables were selected by 'backward selection' using 'cAIC4'package (Saefken et al. 2018) in R. The significant effect of fixed factors was determined using the "Imer" function of the "ImerTest" package (Kuznetsova et al. 2017) also in R. The significance of the random effects was determined using likelihood ratio (LR) test, again in the package "ImerTest". The performance of fitted models was evaluated based on the fit statistics such as Akaike information criterion (AIC) (Akaike 1974) and the marginal R square, which shows the proportion of variance explained by fixed effects (Nakagawa and Schielzeth 2013).

\section{Results}




\section{Diversity effects mediated via functional diversity and functional dominance}

The results of the structural equation models fitted to test the mediated effects of diversity (species richness) on AGC, through functional diversity and functional dominance is summarized in Table 1 and Fig. 3(a). The chi-square value for the "full mediation" model was 24.63 with 14 degrees of freedom and a $p$ value of 0.026 and standardized root mean square residual was 0.076 , indicating slight good fit.

In the "full mediation" model, species richness revealed a significant positive direct effect on the functional richness $\left(R^{2}=0.580 ; \beta=0.76 ; p<.001\right.$; Table 1$)$, but showed no significant positive effect on the AGC ( $B=0.17 ; p=.374 ;$ Table 1$)$. There was also a significant positive effect of species richness on functional evenness $\left(R^{2}=.194 ; ß=-0.44 ; p<.001 ;\right.$ Table 1$)$; the latter, however, exhibited non significant positive effect on the AGC. Further, species richness showed a positive significant effect on functional dispersion $\left(R^{2}=0.157 ; \beta=0.40 ; p<.001 ;\right.$ Table 1$)$, however, non significant positive effect on AGC was found. There was positive and non significant of species richness on functional divergence $(B=0.12 ; P=$ .356; Table 1), which latter, indicates negative and slightly significant effect on the AGC $(B=-0.23 ; P$ $=.084$; Table 1 ) at 0.1 , which would suggest that the mediated effects of species richness were mediated through functional divergence only. In addition, no significant correlation between functional richness and functional evenness ( $B=0.29 ; p=.090$; Table 1 ) was found, which would suggest that the mediated effects of species richness were transmitted by both functional richness and functional evenness.

Out of the three functional dominance metrics, the CWM of SLA and CWM of wood density did not retain any significant path. Only the CWM of maximum plant height showed significant responses to species richness $\left(R^{2}=0.07 ; \beta=0.26 ; p=.040 ;\right.$ Table 1$)$, but showed negative and non significant effect on the AGC $(B=-0.17 ; p=.612$; Table 1). The significant residual correlation of CWM of maximum plant height with CWM of wood density ( $B=0.45 ; p=.003$ and CWM of SLA $(B=0.45 ; p=.003$; Table 1$)$ confirms that the mediated effects of species richness are transmitted via CWM of maximum plant height only.

The partial mediation model was fitted by only adding a direct path from species richness to AGC to the "full mediation" model. The second model (partial mediation) had chi-square value of 19.58 (DF $=12 ; p$ $=.076$, Fig. 3(b) and Table 1), indicating good fit and absence of significant deviations between data and model. There are similarities between the two models in terms of significance and no significant paths (Table 1). However, the "partial mediation" model showed slightly better fits (GFI $=0.947 ; R 2=0.22$; SRMR $=0.071)$ than the "full mediation" model $(\mathrm{GFI}=0.928 ; R 2=0.14 ; \mathrm{SRMR}=0.076)$. The significant influence of added causal path from species richness to AGC was found, suggesting an existing true direct effect of diversity on the AGC. Both models recommend that the effects of species richness on aboveground carbon be mediated via functional diversity and functional dominance, which support for both complementarity hypothesis and selection effect hypothesis.

Table 1 SEM carried out to test the effects of species richness on carbon stocks through functional diversity and functional dominance. 


\begin{tabular}{|c|c|c|c|c|c|c|}
\hline \multirow[t]{2}{*}{ Regression } & Est.st & SE & $P$-value & Est.st & SE & $P$-value \\
\hline & \multicolumn{3}{|c|}{ Partial mediation } & \multicolumn{3}{|c|}{ Full mediation } \\
\hline Path from $S$ to FEve & -0.44 & 0.10 & $<0.001$ & -0.44 & 0.10 & $<0.001$ \\
\hline Path from $S$ to FDis & 0.40 & 0.11 & $<0.001$ & 0.40 & 0.11 & $<0.001$ \\
\hline Path from S to FDiv & 0.12 & 0.13 & 0.356 & 0.12 & 0.13 & 0.356 \\
\hline Path from S to FRic & 0.76 & 0.05 & $<0.001$ & 0.76 & 0.48 & $<0.001$ \\
\hline Path from S to CWM.SLA & 0.10 & 0.14 & 0.474 & 0.09 & 0.14 & 0.475 \\
\hline Path from S to CWM.PHm & 0.26 & 0.13 & 0.040 & 0.26 & 0.13 & 0.040 \\
\hline Path from $S$ to CWM.WD & -0.15 & 0.13 & 0.275 & -0.15 & 0.13 & 0.273 \\
\hline Path from $S$ to $A G C$ & 0.45 & 0.19 & 0.016 & - & - & - \\
\hline Path from FRic to AGC & -0.09 & 0.21 & 0.651 & 0.17 & 0.19 & 0.374 \\
\hline Path from FEve to AGC & 0.14 & 0.17 & 0.422 & 0.05 & 0.17 & 0.784 \\
\hline Path from FDiv to AGC & -0.27 & 0.13 & 0.037 & -0.23 & 0.14 & 0.084 \\
\hline Path from FDis to AGC & 0.19 & 0.18 & 0.275 & 0.26 & 0.18 & 0.143 \\
\hline Path from CWM.PHm to AGC & -0.09 & 0.12 & 0.457 & -0.07 & 0.13 & 0.618 \\
\hline Path from CWM.WD to AGC & 0.18 & 0.15 & 0.250 & 0.13 & 0.16 & 0.434 \\
\hline Path from CWM.SLA to AGC & -0.19 & 0.15 & 0.207 & -0.17 & 0.16 & 0.298 \\
\hline \multicolumn{7}{|l|}{ Fit statistics } \\
\hline Chisq: $19.58(p=.076)$ & & & & \multicolumn{3}{|c|}{ Chisq: $24.63(p=.026)$} \\
\hline DF: 12 & & & & \multicolumn{3}{|c|}{ DF: 13} \\
\hline SRMR: .071 & & & & \multicolumn{3}{|c|}{ SRMR: .076} \\
\hline GFI: .947 & & & & \multicolumn{3}{|c|}{ GFI: .928} \\
\hline
\end{tabular}

Legend: CWM, PHm, SLA, and WD refer to community weight mean, maximum plant height, specific leaf area and wood density respectively. S, species richness; SEM, Structural equation modeling; SE, standard error; Est.std, standardized estimate. Chisq, Chi-square statistic; DF, degree of freedom, indicating the number of paths omitted from the model; $P$, the probability of the data given the model; $P>0.05$. GFI, Goodness fit index; SRMR, Standardized root means square residual.

\section{Effect of environmental variables on aboveground carbon stocks}


There were significant effects of the environmental variables, particularly the slope which explained $7.41 \%$ of the variation of the aboveground carbon (Table 2). However, altitude and aspect gradients showed non-significant effect on the aboveground carbon ( $p=.168$ and .701, respectively; Table 2). Additionally, when accounting for the effects of the altitude, significant effect of species richness on the aboveground carbon was found ( $B=0.78 ; p=.034$; Table 2 ).

Table 2 Simple and multiple linear models testing the effects of elevation, slope, aspect and richness on aboveground carbon (AGC) stock

\begin{tabular}{|c|c|c|c|c|c|c|c|}
\hline & Est. & SE & $\mathrm{t}$ value & $p$-value & BP & DW & VIF \\
\hline Intercept & 27.43 & 19.63 & 1.398 & 0.168 & 0.8 & 2.299 & 1.125 \\
\hline Elevation & -0.004 & 0.007 & -0.551 & 0.584 & & & \\
\hline Adjusted R² (\%) & 1.332 & & & & & & \\
\hline Intercept & 19.899 & 1.731 & 11.5 & $<0.001$ & 0.813 & 2.094 & 1.077 \\
\hline Slope & -0.104 & 0.045 & -2.29 & 0.026 & & & \\
\hline Adjusted R2 (\%) & 7.414 & & & & & & \\
\hline Intercept & 15.92 & 2.145 & 7.42 & $<0.001$ & 0.997 & 2.238 & 1.056 \\
\hline Aspect & 0.183 & 0.472 & 0.387 & 0.701 & & & \\
\hline Adjusted R ${ }^{2}(\%)$ & 1.631 & & & & & & \\
\hline Intercept & -2.809 & 22.01 & -0.128 & 0.898 & 0.13 & 2.238 & 1.309 \\
\hline Elevation & 0.004 & 0.007 & 0.573 & 0.568 & & & \\
\hline Species richness & 0.783 & 0.358 & 2.185 & 0.034 & & & \\
\hline Adjusted R2 (\%) & 5.51 & & & & & & \\
\hline
\end{tabular}

Legend: Est., estimates of regression coefficients; SE, standard errors; BP, $p$-values for Breusch-Pagan tests; DW, Durbin-Watson autocorrelation statistic; VIF, value inflation factor.

\section{Functional diversity and functional dominance effects aboveground carbon (AGC) stock}

The separate linear mixed effects models testing the individual effects of functional diversity metrics showed that FRic $(B=1.02, p=0.042)$ and FDis $(B=16.71, p=<0.001)$ had a significant positive effect on the AGC (Table 3). Both functional divergence $(B=-10.64, p=.485)$ and functional evenness $(B=3.82$, $p=.524$ ) had no significant negative and positive effects on the AGC (Table 3 ). With respect to the combined effects of functional diversity metrics, the significant effects of FDis and FDiv were found after backward selection for the final model (Table 3). The effects of functional diversity on AGC were 
therefore shown by a significant positive effect of functional dispersion $(B=21.36 ; p=<.001$; Table 3 ) and a significant negative effect of functional divergence $(B=-39.18 ; p=.003$; Table 3$)$. Both functional dispersion and functional divergence explained $29 \%$ of the variance of AGC.

Table 3 Linear mixed effects models testing the effects of functional diversity on aboveground carbon stock.

\begin{tabular}{|llllllllll|}
\hline \multicolumn{3}{|c}{ Fixed effects } & \multicolumn{6}{c|}{ Random effects (variance) } \\
\hline & Est. & SE & df & $\operatorname{Pr}(>|\mathrm{t}|)$ & Elevation & Rsd. & Marg. ${ }^{2}$ & AIC \\
\hline (Intercept) & 11.88 & 2.59 & 51.78 & $<0.001$ & 45.20 & 11.22 & 0.07 & 370.55 \\
\hline FRic & 1.02 & 0.49 & 51.99 & 0.042 & & & & \\
\hline (Intercept) & -5.60 & 5.81 & 33.36 & 0.342 & 45.96 & 5.42 & 0.21 & 358.93 \\
\hline FDis & 16.71 & 4.26 & 32.36 & $<0.001$ & & & & \\
\hline (Intercept) & 25.25 & 12.06 & 51.92 & 0.041 & 43.06 & 15.95 & 0.01 & 366.98 \\
\hline FDiv & -10.64 & 15.13 & 51.93 & 0.485 & & & & \\
\hline (Intercept) & 14.27 & 4.08 & 45.70 & $<0.001$ & 38.59 & 19.69 & 0.01 & 368.37 \\
\hline FEve & 3.82 & 5.94 & 43.90 & 0.524 & & & & \\
\hline (Intercept) & 19.26 & 9.71 & 22.79 & 0.059 & 48.39 & 1.31 & 0.29 & 346.72 \\
\hline FDis & 21.36 & 3.17 & 7.38 & $<0.001$ & & & & \\
\hline FDiv & -39.18 & 11.18 & 14.20 & $<0.01$ & & & & \\
\hline
\end{tabular}

Legend: Est., coefficient estimates; $S E$, standard errors; FRic, functional richness; FEve, functional evenness; FDis, functional dispersion; FDiv, functional divergence; Rsd., residual variance; Marg. $R^{2}$, marginal $\mathrm{R}$ square.

Out of the three functional dominance metrics used in this study only CWM of WD showed negative significant effects on the AGC (Table 4). However, CWM of SLA ( $B=-0.09 ; p=.250)$ and CWM of PHm (( $=0.28 ; p=.124)$ revealed negative and positive with non-significant effects on the AGC (Table 4). Furthermore, when testing their combined effects on AGC, CWM of WD was not retained by the final model, and the effects of functional dominance were only shown by positive and significant effects of CWM of maximum plant height and negative non-significant effect of CWM of SLA, with $10.1 \%$ explained variance (Table 4).

The output of mixed effects models of functional diversity and functional dominance showed that the marginal $R$ square (variance explained by fixed factors) in the diversity and AGC relationship was greater 
for functional diversity (29\%) than for functional dominance (10.1\%) (Table 5). While analyzing the combined effect of functional diversity and functional dominance on AGC, the result revealed that $22.4 \%$ of the deviations of AGC were explained by significant effects of functional dispersion and CWM of wood density (Table 5), indicating variation of AGC greater for functional diversity than combined model effects.

Table 4 Linear mixed effects models testing the effects of functional dominance on aboveground carbon (AGC) stock

\begin{tabular}{|lllllllll|}
\hline \multicolumn{3}{|c|}{ Fixed effects } & \multicolumn{6}{c|}{ Random effects (variance) } \\
\hline & Est. & SE & df & $\operatorname{Pr}(>|t|)$ & Elevation & Rsd. & Marg. $R^{2}$ & AIC \\
\hline (Intercept) & 10.99 & 3.82 & 27.82 & 0.008 & 48.45 & 10.51 & 0.02 & 374.55 \\
\hline CWM.PHm & 0.28 & 0.18 & 24.64 & 0.124 & & & & \\
\hline (Intercept) & 23.65 & 5.98 & 49.35 & $<0.001$ & 38.88 & 18.52 & 0.02 & 376.81 \\
\hline CWM.SLA & -0.09 & 0.08 & 49.62 & 0.250 & & & & \\
\hline (Intercept) & 58.57 & 20.48 & 38.21 & $<0.01$ & 49.57 & 8.82 & 0.01 & 376.81 \\
\hline CWM.WD & -70.49 & 34.53 & 38.18 & 0.048 & & & & \\
\hline (Intercept) & 18.89 & 6.31 & 50.27 & 0.004 & 49.06 & 7.29 & 0.101 & 310.86 \\
\hline CWM.SLA & 0.63 & 0.05 & 47.82 & 0.186 & & & & \\
\hline CWM.PHm & 0.43 & 0.15 & 30.91 & $<0.01$ & & & & \\
\hline & & & & & & & & \\
\hline
\end{tabular}

Legend: Est., coefficient estimates; $S E$, standard errors; Rsd., residual variance; Marg. $R^{2}$, marginal $\mathrm{R}$ square; CWM.SLA, community weight mean of specific leaf area; CWM.WD, community weight mean of wood density; CWM. PHm, community weight mean of maximum plant height.

Table 5 Linear mixed effects models testing the combined effects of functional diversity and functional dominance on aboveground carbon (AGC) stock 


\begin{tabular}{|c|c|c|c|c|c|c|}
\hline Model & & & Est. & $S E$ & df & $\operatorname{Pr}(>|t|)$ \\
\hline Functional diversity + & Fixed effects & (Intercept) & 33.70 & 20.19 & 48.24 & 0.102 \\
\hline Functional dominance & & & & & & \\
\hline & & CWM.WD & -63.52 & 29.76 & 34.67 & 0.040 \\
\hline & & FDis & 15.46 & 4.08 & 35.86 & $<0.001$ \\
\hline & Random effects & Elevation & 47.95 & & & \\
\hline & (variance) & & & & & \\
\hline & & Rsd. & .286 & & & \\
\hline & & $\operatorname{Marg} \cdot R^{2}$ & 22.4 & & & \\
\hline & & AIC & 342.60 & & & \\
\hline
\end{tabular}

Legend: Est., coefficient estimates; $S E$, standard errors; df, degree of freedom; CWM.WD, community weight mean of wood density; FDis, functional dispersion.

\section{Discussion}

\section{Species diversity promotes aboveground carbon stocks}

In our study there was a significant and positive effect of species richness on aboveground carbon, after effects of environmental drivers (e.g. Elevation) were accounted for. While this finding in line with some previous studies that controlled for the effects of environmental factors (Ruiz-Jaen and Potvin 2010; Wu et al. 2015; Mensah et al. 2016), it also supports the positive relationship in diverse natural forests; that is, biomass and carbon stocks increase with increasing species diversity. In fact, various local and global studies on forest ecosystems have observed a positive relationship between species richness and forest biomass or carbon (Cavanaugh et al. 2014; Ruiz-Benito et al. 2014; Wu et al. 2015; Mensah et al. 2016). In addition, studies in subtropical forests (Vance-Chalcraft et al. 2010), Spruce dominated forest stands (Wang et al. 2011), Collaborative forests in Terai, Nepal (Mandal et al. 2013), and tropical forests (Barrufol et al. 2013) have also reported increases in biomass productivity with increasing diversity.

It noted that increasing species richness, would be increased carbon storage in forest ecosystems because higher taxonomic diversity would lead to a higher proportion of large trees (Ruiz-Jaen and Potvin 2010; Ruiz-Benito et al. 2014). Some other recent evidences showed that a positive effect of species richness on aboveground carbon might also be explained through the biotic interactions such as facilitation, where by some species could enhance soil fertility (e.g. by fixing nitrogen) for the productivity of other species. This fact is even always used to support the reason why mixed species, communities of plantations are more productive than mono-specific stands (Mensah et al. 2016). Although it might also 
be well promising that increasing species richness increases the probability of inclusion of highly productive and naturally dominant species (Ruiz-Benito et al. 2014; Mensah et al. 2018).

While our result in the dry evergreen Afromontane forest supports the positive species richnessaboveground carbon relationship, it should be well known that finding of the inverse effect also exists. For example, report by Ruiz-Jaen and Potvin (2011) from natural forest of Barro Colorado Island in Central Panama. Other studies have reported null or negative relationship between aboveground carbon and species diversity in forest ecosystems (Zhang et al. 2014; Whittaker and Heegaard, 2003). These discrepancy findings suggest that the effects of diversity on forest carbon may vary with other factors such as the types, sites and the successional stages of the forests (Lasky et al. 2014; Wu et al. 2015), and also the specific dimension of the diversity measure used (Vance-Chalcraft et al. 2010; Lasky et al. 2014).

\section{Effects of environmental factors on tree aboveground carbon stock}

In this study we did not found significant effect of elevation on tree aboveground carbon stock. In line with our finding, Cavanaugh et al. (2014) and Mensah et al. (2016) reported no significant relationship between forest carbon and elevation. However, this finding runs contrary to many previous studies that tested the relationships between elevation and biomass or carbon stock (Ensslin et al. 2015). On the one hand, some scholars found that biomass and carbon stocks could decrease with increasing elevation (Moser et al. 2007). On the other hand, studies observed positive correlation between increasing tree carbon and increasing elevation (Zhang et al. 2018; Zhu et al. 2010). This lack of clarity on the relationship between altitude and forest biomass may be partly due to the variation in the elevation range among studies.

Unlike altitude and aspect, slope showed significant effect, and accounted for $5.51 \%$ of aboveground carbon variance, evidencing that variations in carbon stocks can result from topological constraints, particularly difference in slope. Consistent with our results, slope has been identified as an important environmental gradient that affects tree carbon (de Castilho et al. 2006; Chave et al. 2003). This is because, aboveground carbon is inherently related to wood and biomass production, the effect of slope can be seen as prior impacts of environment on availability of resources (Luizao et al. 2004), which in turn influence forest dynamics. For instance, steeper slope will speed up nutrients, water runoff, and constrain trees and will also favor highly water and nutrient efficient species against others. Taking this into account, it follows that tree growth and biomass production can be potentially declined at higher slope areas, as results of moisture and nutrient stress (Clark et al. 2010; Durán et al. 2015), whereas flat and gentle slope areas would allow for more water availability, to which plant would likely respond positively. The significant effect of slope supports the fact that ecosystem functions in general and biomass carbon stock in particular are environment- structured (Wu et al. 2015).

\section{Diversity effects mediated via functional diversity and functional dominance}

In the recent decades, interest has increased significantly in determining the multiple biodiversity measures and ecosystems functioning relationships. One of the most commonly examined relationships 
is that between species richness and productivity (Ruiz-Jaen and Potvin 2010).

The use of different measures of biodiversity component to provide additional mechanisms motivating the effects of biodiversity on carbon stocks has also gained increasing interest in recent years (Cadotte et al. 2011; Conti and Díaz 2013; Finegan et al. 2015; Lasky et al. 2014; Ruiz-Benito et al. 2014; VanceChalcraft et al. 2010; Ziter et al. 2013). Accordingly, functional diversity and dominance metrics were also examined in this study. While most of these studies tended to compare the relative effects of species richness and other biodiversity components on aboveground carbon stocks, by assuming that these effects were mediated via functional diversity and functional dominance. In this study the structural equation modeling results confirm this assumption and this is, therefore, supports the need to explore beyond species richness to elucidate the mechanisms that drive relationship between diversity and productivity. The results further support the hypothesis that both niche complementarity and selection effects are not exclusively affecting carbon storage in tropical forests (Cavanaugh et al. 2014; Wu et al. 2017). Therefore, diversity (species richness) predicts carbon stock through effects of both functional diversity and functional dominance, partly because these diversity components are based on specific functional traits, which would reflect functional variations among the species (Di'az and Cabido 2001; Mensah et al. 2016). Indeed, in this finding increased species richness indirectly accounted for differences among species, in terms of ecological niche and resource use.

\section{Functional diversity effects on aboveground carbon stock}

The linear mixed models were used to examine the effects of functional diversity measures on tree aboveground carbon in Dindin dy evergreen Afromontane forest of southeast Ethiopia. Out of the four functional diversity metric used in this study, only functional richness and functional dispersion were found to significantly explain variation in aboveground carbon stock. There is a recent scientific evidence for functional diversity effects on biomass and carbon. Yuan et al. (2018) observed a significant effect of functional evenness on aboveground carbon in temperate mixed forests. Similarly, in tropical rain forests of Bolivia, Brazil, and Costa Rica, Finegan et al. (2015) found functional richness among other functional diversity indices as significant predictor for biomass variation. A study by Ziter et al. (2013) in unmanaged forest fragments in Quebec showed significant and positive relationships between functional dispersion and aboveground carbon. Other study by Finegan et al. (2014) reported significant but negative effects of the functional richness on stand biomass in tropical forests. While in this study, these functional diversity indices have their specific biological meaning, the positive effect of functional richness on the aboveground carbon might be due to functional richness being positively correlated with species richness (refer SEM output; Masonet al. 2005).

Functional diversity has been dissected into four relatively independent components: functional richness FRic, evenness FEve, divergence FDiv (Villeger et al. 2008; Mouchet et al. 2010) and dispersion FDis (Laliberte and Legendre 2010). These indices quantify the trait hypervolume of the community (FRic, FDis) and the distribution of abundance or biomass of the species in this volume (FEve, FDiv and FDis). Both these functional characteristics may measure niche complementarity, and therefore increment of 
ecosystem processes by functional trait variety. The functional would increase carbon stock because species with different traits would differ in resource use, and would more efficiently use the resources available within the community for higher growth and productivity, indicating the importance of niche complementarity effects in facilitating ecosystem processes (Finegan et al. 2015). Unlike functional richness, functional evenness and functional dispersion, functional divergence did not show any relationship with species richness and show no significant influence on aboveground carbon. According to Laliberte and Legendre (2010), the functional dispersion is the mean distance of each species, weighted by its relative abundances, to the centroid of all species in a community. Therefore, both functional richness and functional dispersion relate to the niche space or volumes of niche space, and functional diversity as measured here could reflect some form of "niche differentiation" (Carroll et al. 2011). Niche differentiation is expressed as the beta niche of species, i.e. differentiating species with different optima between communities across environmental gradients (Weiher and Keddy 1995; Silvertown et al. 2006). A greater functional diversity, that is, greater value and range of functional traits, would reflect not only the magnitude of "niche differentiation", but also the differences in resource utilization by species, thus promoting diversity effects on ecosystem functioning. This is consistent with Zhu et al. (2016) who observed increasing niche difference contributes to species coexistence and positive diversity effects on biomass productivity.

\section{Functional dominance effects on aboveground carbon stock}

Community weighted mean (CWM) functional trait values, which are community trait values weighted (selection effect) by species abundances (Muscarella and Uriarte 2016; Thukar and Chawla 2019) used to reflects locally optimal strategies of a community and to predict functional dominance effects. CWM functional traits as functional dominance metric could be used to elucidate on ecological fitness by resource competition ability and environmental filtering (Cornwell and Ackerly 2009; Kraft et al. 2015). Therefore, functional dominance could indicate some aspect of "relative performance or fitness differences" between competitors for limiting resources (Cadotte et al. 2011; Carroll et al. 2011). The dominant functional traits (high wood density and low specific leaf area) in the stressful areas are indicative of a stress tolerant life history strategy (Chapman and McEwan 2018). Moreover, the finding that functional dominance significantly affected tree carbon storage is in line with the previous finding that the magnitude of "relative fitness differences" strengthens the influence of diversity on biomass productivity (Carroll et al. 2011). In this study the functional dominance effects varied with the functional trait. Functional traits are those attributes of an organism or a part of an organism which strongly influences fitness through their effects on the overall structure, function, and diversity of ecosystems (Wieczynski et al. 2019). Particularly, CWM of wood density showed negative and significant effect on aboveground carbon stocks. It is not surprising given that wood density is a potential predictor of tree biomass, which highly correlates with the carbon stock. There are some evidences that CWM of wood density is negatively related to the biomass increment, as being good predictor of individual tree diameter increments (Finegan et al. 2015). After evaluating biomass stocks in tropical forests, some scholars found that AGC-wood density relationship varies from negative to null to positive depending on the forest community and forest identity (Baker et al. 2004; Stegen et al. 2009). In case of the present finding about 
CWM of wood density indicates that low wood density species grow faster and expect to store more biomass; therefore, it recommends that conserving and planting low wood density species would likely help to increase the carbon stock.

In analysis of combined effects of functional dominance metrics only CWM of specific leaf area and of maximum plant height were retained in the final model, with maximum plant height being the significant predictor. This is most likely tree height is a key factor for species-specific or multispecies biomass regressions. Ali (2015) suggest that strong dominance by tall and conservative species, rather than a set of coexisting species with diverse heights and exploitative nature, results in greatest carbon stocks in natural forest ecosystems. Therefore, the positive and significant relationship between CWM of maximum plant height and carbon stocks indicates the potential importance of characteristics of dominant and adult trees for ecosystem functioning and productivity, thus supporting the selection effects hypothesis.

\section{Functional diversity and functional dominance partly effects aboveground carbon stocks}

In testing the proportion of variation explained by the selection effect and niche complementarity mechanisms, functional diversity explained more variation of aboveground carbon than functional dominance (Tables 3 and 4). Unfortunately, this rejects the second hypothesis of this study, and suggests that niche complementarity effects appear to be more important than selection effects. This finding consistent with study by Mensah et al. (2016) supports that functional diversity results in more variance in aboveground carbon than selection effects. In contrary, study by Finegan et al. (2015), Ruiz-Jaen and Potvin's (2011) revealed that selection effects more important for the aboveground biomass and carbon storage in tropical forests. The reason for this discrepancy is that in this study, functional dominance metrics (community weight mean of functional traits) were estimated using species relative abundance, but a study by Ruiz-Jaen and Potvin (2011) and Finegan et al. (2015) used species relative basal area and species relative biomass, respectively, as weighting variable. As noted by Mensah et al. (2016), the strength of relationship between community weight mean of functional traits and the ecosystem function of interest could depend on the weighting variables. Therefore, community weighted mean values of functional trait weighted by biomass or basal area as weighting variables would likely show stronger relation with biomass and carbon than abundance-based communities mean values.

In examining joint effects, the present finding supports the thought that these two hypotheses (niche complementarity and selection effects) are not mutually exclusive, and can contribute to ecosystem functioning. Previous evidence of both complementarity and selection effects on ecosystem function suggests they can also contribute at different proportions at different times of ecosystem services (Fargione et al. 2007). Both complementarity and selection effects mutually promote species coexistence. As reason out by Mensah et al. (2016), these two hypotheses could even be the outcome of interactions of the "relative fitness differences" and the "niche differences", whereby some species' populations could be suppressed by dominant competitors, to allow effective utilization of the available resources. In this study the selection effects are strongly mediated through specific maximum plant 
height, which indicates the effect of dominant species and suggests a possible competitive exclusion in terms of utilization of resources (refer SEM e.g., sun light).

\section{Conclusion}

This study examined the relationship between diversity and carbon stock in dry evergreen Afromontane forest of Southeast Ethiopia and showed that taxonomic diversity (species richness) predicts carbon storage through functional diversity and functional dominance. Further, the study noted that both the niche complementarity and selection hypotheses are important for carbon Stock. On the other hand, carbon stock variations explained by functional diversity (niche complementarity effects) were greater than functional dominance effects (selection effects). Additionally, functional dominance effects were strongly transmitted through the CWM of maximum plant height, indicating the importance of forest vertical stratification for diversity and carbon relationship. Therefore, complementary effects would be induced also by complementary light use efficiency of species and trees growing in the understory layer. This study recommends that future research on the relation between diversity and forest carbon to be oriented toward a perspective of forest canopy (or dominant species vs. other species), to contribute additional insights into our understanding of biodiversity and ecosystem function relationship.

\section{Abbreviations}

AGC: Above-ground carbon; AGB: Above-ground biomass; AIC: Akaike's information criterion; a.s.l: Above sea level; cAIC4: Conditional Akaike's information criterion; BP: Breusch-Pagan tests; oC: Degree Celsius; CWM: Community weight mean; D: stem diameter at breast height; DW: Durbin-Watson statistics ; FRic: Functional richness; FEve: Functional evenness; FDiv: Functional divergence; FDis: Functional dispersion; GFI: Goodness of fit index; GPS: Global positioning system; H: Plant height; kg: kilogram; LMMs: Linear mixed-effects models; LR: Likelihood ratio; MAP: Mean annual precipitation; MAT: Mean annual temperature; PHm: Maximum plant height; S: Species richness; SEM: Structural equation modeling; SLA: Specific leaf area; SRMR: Standardized root mean residual; W: Shapiro-Wilk tests; WD: Wood density; VIF: Value inflation factor; $\rho$ : Stem wood density; $\chi 2$ : Chi-square.

\section{Declarations}

\section{Ethics approval and consent to participate}

Not applicable.

\section{Consent for publication}

Not applicable.

\section{Availability of data and materials}


The datasets used and/or analyzed during the current study are available from the corresponding author on reasonable request.

\section{Competing interests}

We have no competing interests.

\section{Funding}

Funding for this research was obtained from Oda Bultum University, Ethiopia.

\section{Authors' contributions}

Mengistu Teshome, Zebene Asfaw and Muktar Mohammed read and approved the final manuscript. Mengistu Teshome and Zebene Asfaw conceived the presented idea and developed the theory and analytical methods. Mengistu Teshome also planned and carried out the measurements. Mengistu Teshome, Zebene Asfaw and Muktar Mohammed discussed the methodologies and results. Mengistu Teshome wrote the manuscript with assistance from Zebene Asfaw and Muktar Mohammed. All authors read and approved the final manuscript.

\section{Acknowledgments}

We appreciate the collaboration of Oromia forest and Wild life enterprise, Dindin district workers for their help during the fieldwork in the Dindin natural forest. Besides, we thank Mr. Mekonnen Beyene (Oda Bultum University, Ethiopia) for his collaboration collecting vegetation samples from all the plots of this study. The Oda Bultum University is also acknowledged for offering a postgraduate study opportunity for the first author. In addition, we thank Dr Motuma Tolera (Hawassa University, Ethiopia) and Dr Dong Gill Kim (Hawassa University, Ethiopia) for their valuable suggestions for this paper.

\section{References}

1. Akaike H (1974) A new look at the statistical model identification. IEEE Trans Automat Contr 19(6): 716-723.

2. Baker TR, Phillips OL, Malhi Y, Almeida S, Arroyo L, et al. (2004) Variation in wood density determines spatial patterns in Amazonian forest biomass. Glob Chang Biol. 10: 545-562. doi: 10.1111/j.13652486.2004.00751.x

3. Barrufol M, Schmid B, Bruelheide H, Chi X, Hector A, Ma K. ..., Niklaus PA (2013) Biodiversity promotes tree growth during succession in subtropical forest. PLOS ONE 8: 1-9.

4. Cadotte MW, Carscadden K, Mirotchnick N (2011) Beyond species: functional diversity and the maintenance of ecological processes and services: Review. J Appl Ecol. 48: 1079-1087. doi:10.1111/j.1365-2664.2011.02048.x 
5. Carroll IT, Cardinale B, Nisbet RM (2011) Niche and fitness differences relate the maintenance of diversity to ecosystem function. 92: 1157-1165.

6. Casanoves F, Pla L, Di Rienzo J A, Di'az S (2011) FDiversity: a software package for the integrated analysis of functional diversity. Methods Ecol. Evol. 2: 233-237. doi: 10.1111/j.2041210X.2010.00082.x

7. Cavanaugh KC, Gosnell JS, Davis SL, Ahumada J, Boundja P, Clark DB, Andelman S (2014) Carbon storage in tropical forests correlates with taxonomic diversity and functional dominance on a global scale. Glob. Ecol. Biogeogr. 23:563-573.

8. Chapman JI, McEwan RW (2018) The Role of Environmental Filtering in Structuring Appalachian Tree Communities: Topographic Influences on Functional Diversity Are Mediated through Soil Characteristics. Forests 9: 19.

9. Chave J, Goodman RC, Henry M, Martínez-Yrízar A, Mugasha WA, Muller-Landau HC (2014) Improved allometric models to estimate the aboveground biomass of tropical trees.Glob.Chang. Biol. 20: 3177-3190.

10. Chave J, Condit R, Lao S, Caspersen JP, Foster RB, Hubbell SP (2003) Spatial and temporal variation of biomass in a tropical forest: Results from a large census plot in Panama. J Ecol 91: 240-252.

11. Clark DB, Clark DA, Oberbauer SF (2010) Annual wood production in a tropical rain forest in NE Costa Rica linked to climatic variation but not to increasing CO2. Glob. Chang. Biol. 16: 747-759.

12. Conti G, Díaz S (2013) Plant functional diversity and carbon storage-an empirical test in semi-arid forest ecosystems. J Ecol 101: 18-28. doi: 10.1111/1365-2745.12012

13. Cornwell WK, Ackerly DD (2009) Community assembly and shifts in plant trait distributions across an environmental gradient in coastal California. Ecological Monographs 79(1): 109-126.

14. Díaz S, CabidoM (2001) Vive la différence: plant functional diversity matters to ecosystem processes: Review. TRENDS in Ecol. Evol. 16 (11):646-655.

15. Durán SM, Sánchez-Azofeifa GA, Rios RS, Gianoli E (2015) The relative importance of climate, stand variables and liana abundance for carbon storage in tropical forests. Glob Ecol Biogeogr 24: 939949.

16. Ensslin A, Rutten G, Pommer U, Zimmermann R, Hemp A, Fischer M (2015) Effects of elevation and land use on the biomass of trees, shrubs and herbs at Mount Kilimanjaro. Ecosphere 6: 45.

17. Fan Y, Chen J, Shirkey G, John R, Wu SR, Park Hand Chao C (2016) Applications of structural equation modeling (SEM) in ecological studies: an updated review. Ecol. Process. 5:19. DOI 10.1186/s13717-016-0063-3

18. Feldpausch TR, Lloyd J, Lewis SLC, Quesada A, Arets EJMM, Berry NJ, Bird M, Brondizio ES, Camargo P. de, Chave J, Domingues TF, Drescher M, Fearnside PM, Franc, a MB, Fyllas NM, AffumBaffoe K, Djagbletey G. Lopez-Gonzalez G, Hladik A, Higuchi N, Hunter MO, lida Y, Salim KA, Kassim AR, Keller M, King DA, Lovett JC, Marimon BS, Marimon-Junior BH, Lenza E, Marshall AR, Mitchard TA, Moran EF, Nelson BW, Nilus R, Nogueira EM, Palace M, Peh KS-H, Raventos MT, Reitsma JM, Saiz 
G, Schrodt F, Sonke B, Tan S, White L, Woll H (2012) Tree height integrated into pantropical biomass forest estimates. Biogeosciences 9: 3381-3403.

19. Finegan B, Peña-Claros M, de Oliveira A, Ascarrunz N, Bret-Harte MS, Carreño-Rocabado G, ... , Poorter $L$ (2014) Does functional trait diversity predict above-ground biomass and productivity of tropical forests? Testing three alternative hypotheses. J Ecol 103(1): 191-201. doi:10.1111/13652745.12346

20. Gairola S, Sharma CM, Ghildiyal SK, Suyal S (2011) Live tree biomass and carbon variation along an altitudinal gradient in moist temperate valley slopes of the Garhwal Himalaya (India). Curr. Sci. 100: 1862-1870.

21. Galecki A, Burzykowski T (2013) Linear Mixed-Effects Models Using R: A Step-by-Step Approach, Springer Texts in Statistics. DOI 10.1007/978-1-4614-3900-4.

22. Geldenhuys CJ (2002) Tropical Secondary Forest Management in Africa: Reality and Perspectives; Food and Agriculture Organization: Rome, Italy.

23. Gómez DR, Watterson JD, Americano BB, Ha C, Marland G, Matsika E, et al. (2006) IPCC guidelines for national greenhouse gas inventories. Hayama: Institute for Global Environmental Strategies.

24. Grime JP, 1998. Benefits of plant diversity to ecosystems: Immediate, filter and founder effects. Journal of Ecology 86: 902-910.

25. Jerzy S, Anna G (2007) Above-ground standing biomass and tree species diversity in natural stands of Central Europe. J. Veg. Sci. 18:563-570. https://doi.org/10.1111/j.1654-1103.2007. tb02569.x.

26. Kattge J, Diaz S, Lavorel S, Prentice IC, Leadley P, Bönisch G, ... Wirth C (2011) TRY- a global database of plant traits. Glob Chang Biol 17: 2905-2935.

27. Kraft NJB, Adler PB, Godoy O, James EC, Fuller S, Levin jM (2015) Community Phylogenetics and Ecosystem Functioning: Community assembly, coexistence and the Environmental fltering metaphor. Funct Ecol. 29: 592-599. doi: 10.1111/1365-2435.12345

28. Kuznetsova A, Brockhoff PB, Christensen RHB (2017) ImerTest Package: Tests in Linear Mixed Effects Models. J. Softw. 82(13): 1-26. doi:10.18637/jss.v082.i13

29. Laliberte $E$, Legendre $P$ (2010) A distance-based framework for measuring functional diversity from multiple traits. Ecol. 91(1): 299-305

30. Lasky JR, Uriarte M, Boukili VK, Erickson DL, John Kress W, Chazdon RL (2014) The relationship between tree biodiversity and biomass dynamics changes with tropical forest succession. Ecol. Lett. 17(9): 1158-1167. doi:10.1111/ele.12322

31. Li S, Lang X, Liu W, Ou3 G, Xu3 H, Su J (2018) The relationship between species richness and aboveground biomass in a primary Pinuskesiya forest of Yunnan, southwestern China. PLoS ONE 13(1): 0191140. https://doi.org/10.1371/journal.pone.0191140

32. Luizao RCC, Luizao FJ, Paiva RQ, Monteiro TF, Sousa LS, Kruijt B (2004) Variation of carbon and nitrogen cycling processes along a topographic gradient in a central Amazonian forest. Glob Chang Biol 10: 592-600. 
33. Magurran AE (2004) Measuring Biological Diversity. Blackwell Science Itd, Australia.

34. Maire V, Wright IJ, Prentice IC, Batjes NH, Bhaskar R, van Bodegom PM. ..., Santiago LS (2015) Global effects of soil and climate on leaf photosynthetic traits and rates. Glob. Ecol. Biogeogr. 24(6): 706717.

35. Mandal RA, Jha PK, Dutta IC, Karmacharya S (2013) Relationship between Carbon Stock and Plant Biodiversity in Collaborative Forests in Terai, Nepal. ISRN Botany 1-7.

36. Mason NWH, Mouillot D, Lee WG, Wilson JB (2005) Functional richness, functional evenness and functional divergence: the primary components of functional diversity. Oikos 111: 112-118.

37. Mensah S, du Toit B, Seifert T (2018) Diversity-biomass relationship across forest layers: implications for niche complementarity and selection effects. Oecologia 187:783-795.

38. Mensah S, Veldtman R, Assogbadjo AE, GlèlèKakaï R, Seifert T (2016) Tree species diversity promotes aboveground carbon storage through functional diversity and functional dominance. Ecol. Evol. 6: 7546-7557.

39. Morin X, Fahse L, Scherer-Lorenzen M, Bugmann H (2011) Tree species richness promotes productivity in temperate forests through strong complementarity between species. Ecol. Lett. 14:1211-1219. https://doi.org/10.1111/j.1461-0248.2011.01691.x

40. Moser G, Hertel D, Leuschner C (2007) Altitudinal change in LAl and stand leaf biomass in tropical montane forests: A transect study in ecuador and a pan-tropical meta-analysis. Ecosystems 10, 924-935.

41. Mouchet M A, Villeger S, Norman WH, Mason NWH, Mouillot D (2010) Functional diversity measures: an overview of their redundancy and their ability to discriminate community assembly rules. Funct. Ecol. 24: 867-876. doi: 10.1111/j.1365-2435.2010.01695.x

42. Muscarella R, Uriarte $M$ (2016) Do community-weighted mean functional traits reflect optimal strategies? Proc R Soc B BiolSci 283:20152434. https ://doi.org/10.1098/rspb.2015.2434

43. Nakagawa $S$, Schielzeth $H$ (2013) A general and simple method for obtaining $R^{2}$ from generalized linear mixed- effects models. Methods Ecol. Evol. 4: 133-142.

44. Poorter1 L, van der Sande MT, Thompson J, Arets EJMM, Alarcón A, Álvarez-Sánchez J, Ascarrunz N, Balvanera $\mathrm{P}$ et al. (2015) Diversity enhances carbon storage in tropical forests. Ecol. Biogeogr. 1-15. DOI: $10.1111 /$ geb.12364

45. Prado-junior JA, Schiavini I, Vale VS, Arantes CS, Van Der Sande MT, Lohbeck M, Poorter L (2016) Conservative species drive biomass productivity in tropical dry forests. J Ecol. 104: 817-827. https://doi.org/10.1111/1365-2745.12543

46. Reich PB, Knops J, Tilman D, Craine J, Ellsworth D, Tjoelker M, Lee T, Wedin D, Naeem S, Bahauddin D, Hendrey G, Jose S, Wrage K, Goth J, Bengston W (2001) Plant diversity enhances ecosystem responses to elevated $\mathrm{CO}_{2}$ and nitrogen deposition. Nature 410: 809-810.

47. Ruiz-Benito P, Gómez-Aparicio L, Paquette A, Messier C, Kattge J, Zavala MA (2014) Diversity increases carbon storage and tree productivity in Spanish forests. Ecol. Biogeogr. 23: 311-322. 
48. Ruiz-Jaen MC, Potvin C (2010) Can we predict carbon stocks in tropical ecosystems from tree diversity? Comparing species and functional diversity in a plantation and a natural forest. New Phytol. 1-10. doi: 10.1111/j.1469-8137.2010.03501.x

49. Ruiz-Jaen MC, Potvin C (2011) Tree Diversity Explains Variation in Ecosystem Function in a Neotropical Forest in Panama. BIOTROPICA 42(6): 638-646. 10.1111/j.1744-7429.2010.00631.x

50. Saefken B, Ruegamer D, Kneib T, Greven S (2018) Conditional Model Selection in Mixed-Effects Models with cAIC4. https://arxiv.org/abs/1803.05664

51. Stegen JC, Swenson NG, Valencia R, Enquist BJ, Thompson J (2009) Above- ground forest biomass is not consistently related to wood density in tropical forests. Ecol. Biogeogr. 18: 617-625.

52. Thakur D, Chawla A (2019) Functional diversity along elevational gradients in the high altitude vegetation of the western Himalaya. Biodivers. Conserv., https://doi.org/10.1007/s10531-019-01728$5 \backslash$

53. Tilman D, Knops J, Wedin D, Reich P, Ritchie M, Siemann E (1997) The influence of functional diversity and composition on ecosystem processes. Science 277: 1300-1302.

54. Vance-Chalcraft HD, Willig MR, Cox SB, Lugo AE, Scatena FN (2010) Relationship Between Aboveground Biomass and Multiple Measures of Biodiversity in Subtropical Forest of Puerto Rico. BIOTROPICA 42(3): 290-299. 10.1111/j.1744-7429.2009.00600.x

55. Wang W, Lei X, Ma Z, Kneeshaw DD, Peng C (2011) Positive relationship between aboveground carbon stocks and structural diversity in spruce-dominated forest stands in New Brunswick, Canada. For. Sci. 57:506-515. https ://doi.org/10.1111/oik.01525

56. Whittaker R, Heegaard E (2003) What is the observed relationship between species richness and productivity? Ecol. 84:3384-3390. https://doi.org/10.1007/s00442-003-1343-z

57. Wieczynski DJ, Boyle B, Buzzard V, Duran SM, Henderson AN, Hulshof CM, Kerkhoff AJ, McCarthy M C, Michaletz ST, Swenson NG, Asner GP, Bentley LP, Enquist BJ, Savage VM (2019) Climate shapes and shifts functional biodiversity in forests worldwide. PNAS 116(2): 587-592.

58. Wu H, Xiang W, Fang X, Lei p, Ouyang S, Deng X (2017) Tree functional types simplify forest carbon stock estimates induced by carbon concentration variations among species in a subtropical area Scientific Report 7: 4992. DOI:10.1038/s41598-017-05306-z

59. Yuan Z, Wang S, Ali A, Gazol A, Ruiz-Benito P, Wang X, Lin F, Ye J, Hao Z, Loreau M (2018) Aboveground carbon storage is driven by functional trait composition and stand structural attributes rather than biodiversity in temperate mixed forests recovering from disturbances. Ann. For. Sci. 75: 67. https://doi.org/10.1007/s13595-018-0745-3

60. Zanne AE, Lopez-Gonzalez G, Coomes DA, llic J, Jansen S, Lewis SL, Miller RB, Swenson NG, Wiemann MC, Chave J (2009) Global wood density database. Dryad. Identifier: http://hdl.handle.net/10255/dryad.235.

61. Zhang J-T, Li M, Nie E (2014) Pattern of functional diversity along an altitudinal gradient in the Baihua Mountain Reserve of Beijing, China. Braz J Bot. 37(1):37-45. DOI 10.1007/s40415-014-00474 
62. Zhang Y, Chen HYH (2015) Individual size inequality links forest diversity and above-ground biomass. J Ecol. 103: 1245-1252. https://doi.org/10.1111/1365-2745.12425.

63. Zhu J, Jiang L, Zhang Y (2016) Relationships between functional diversity and aboveground biomass production in the Northern Tibetan alpine grasslands. Scientific Reports 6:34105. DOI: 10.1038/srep34105

64. Zhu B, Wang X, Fang J, Piao S, Shen H, Zhao S, Peng C (2010) Altitudinal changes in carbon storage of temperate forests on Mt Changbai, Northeast China. J. Plant Res. 123, 439-452.

65. Ziter C, Bennett EM., Gonzalez A (2013) Functional diversity and management mediate aboveground carbon stocks in small forest fragments. Ecosphere 4(7): 85. http://dx.doi.org/10.1890/ES1300135.1

66. Zuur A F, leno EN, Walker N, Saveliev AA, Smith GM (2009) Mixed effects models and extensions in ecology with R. New York, NY: Springer New York.

\section{Figures}

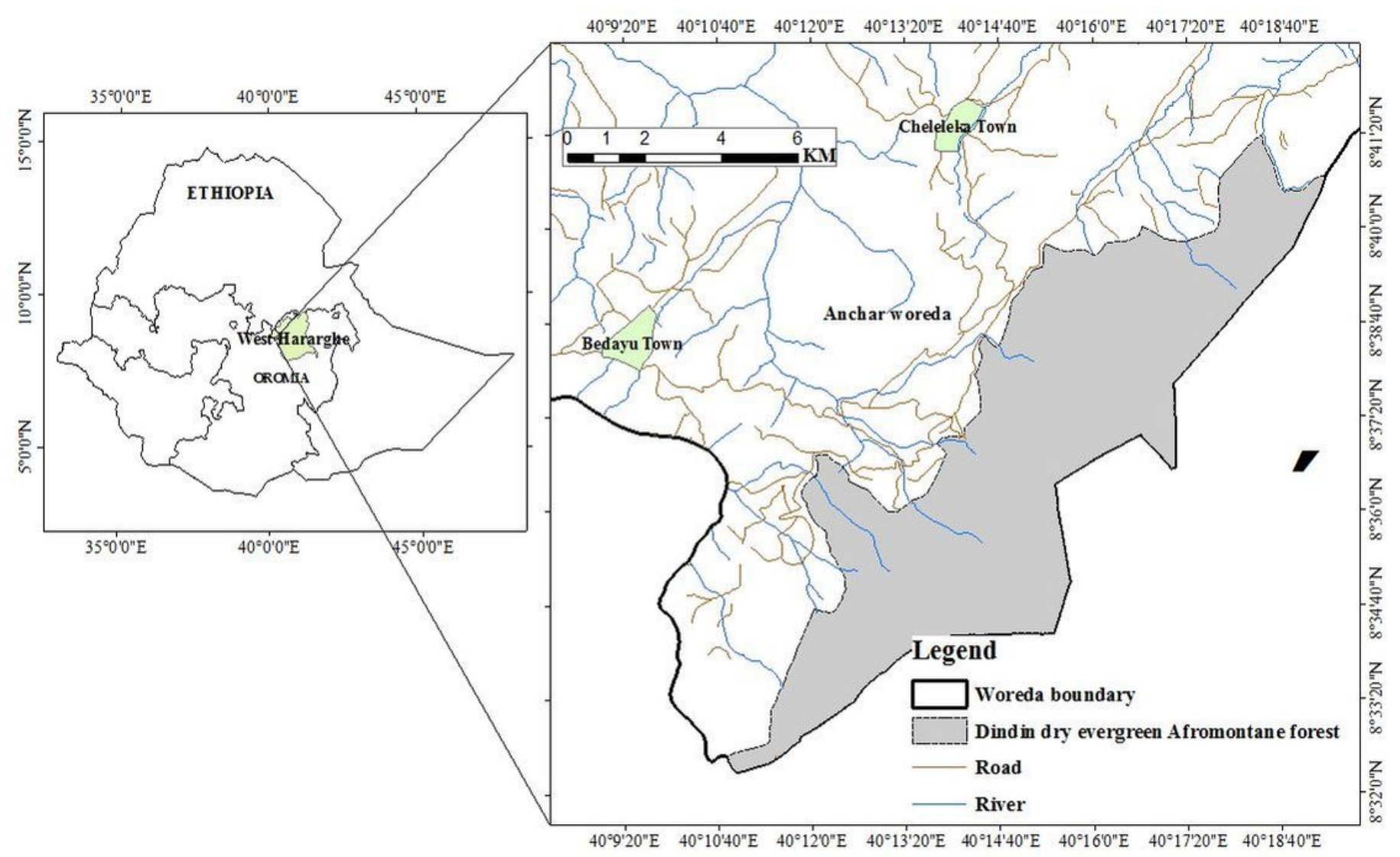

\section{Figure 1}

Study area map. 


\subsection{C $\quad 804 \mathrm{~mm}$}

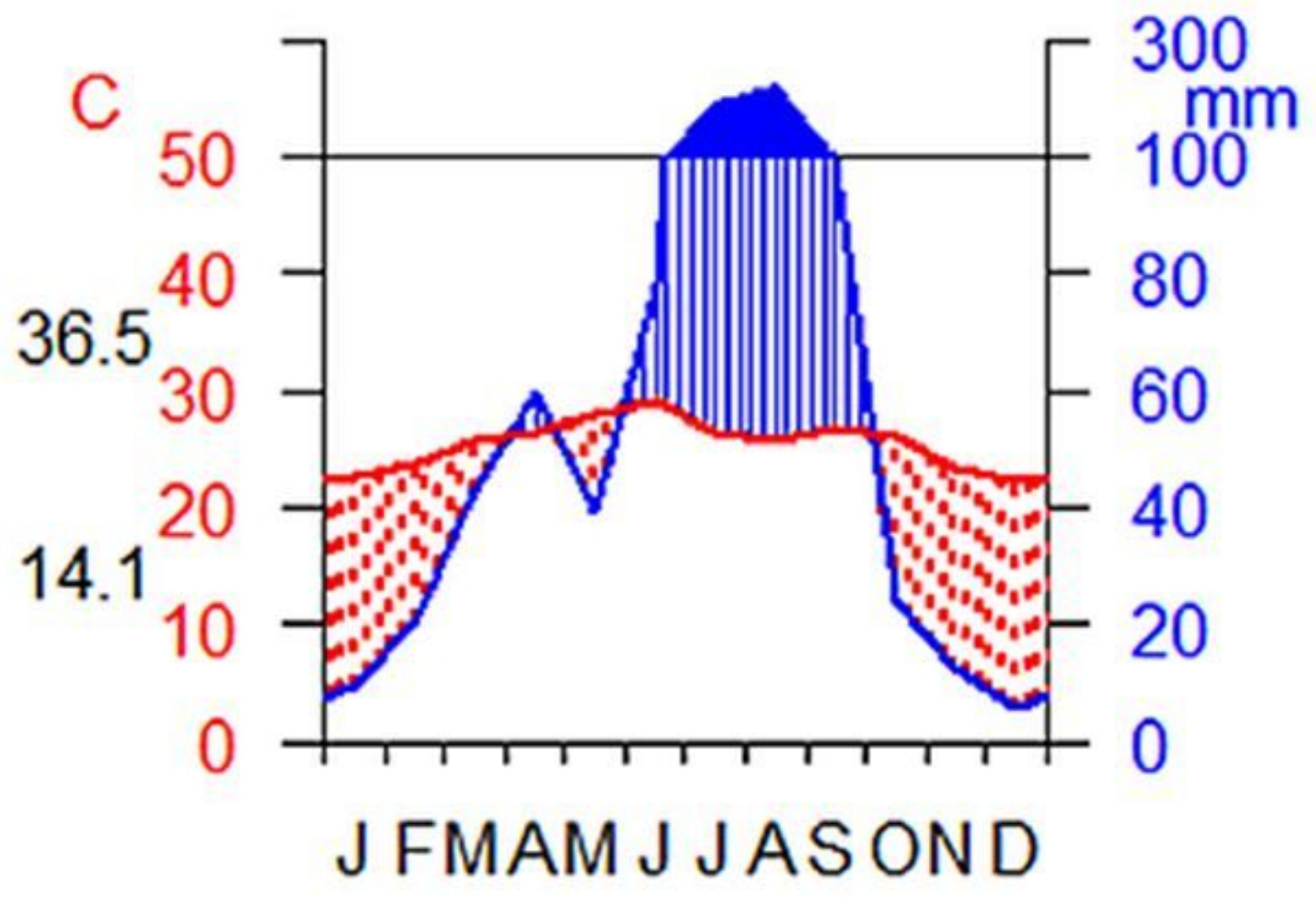

Figure 2

Climate Diagram of study area (values generated using New_LocClim. See text). 

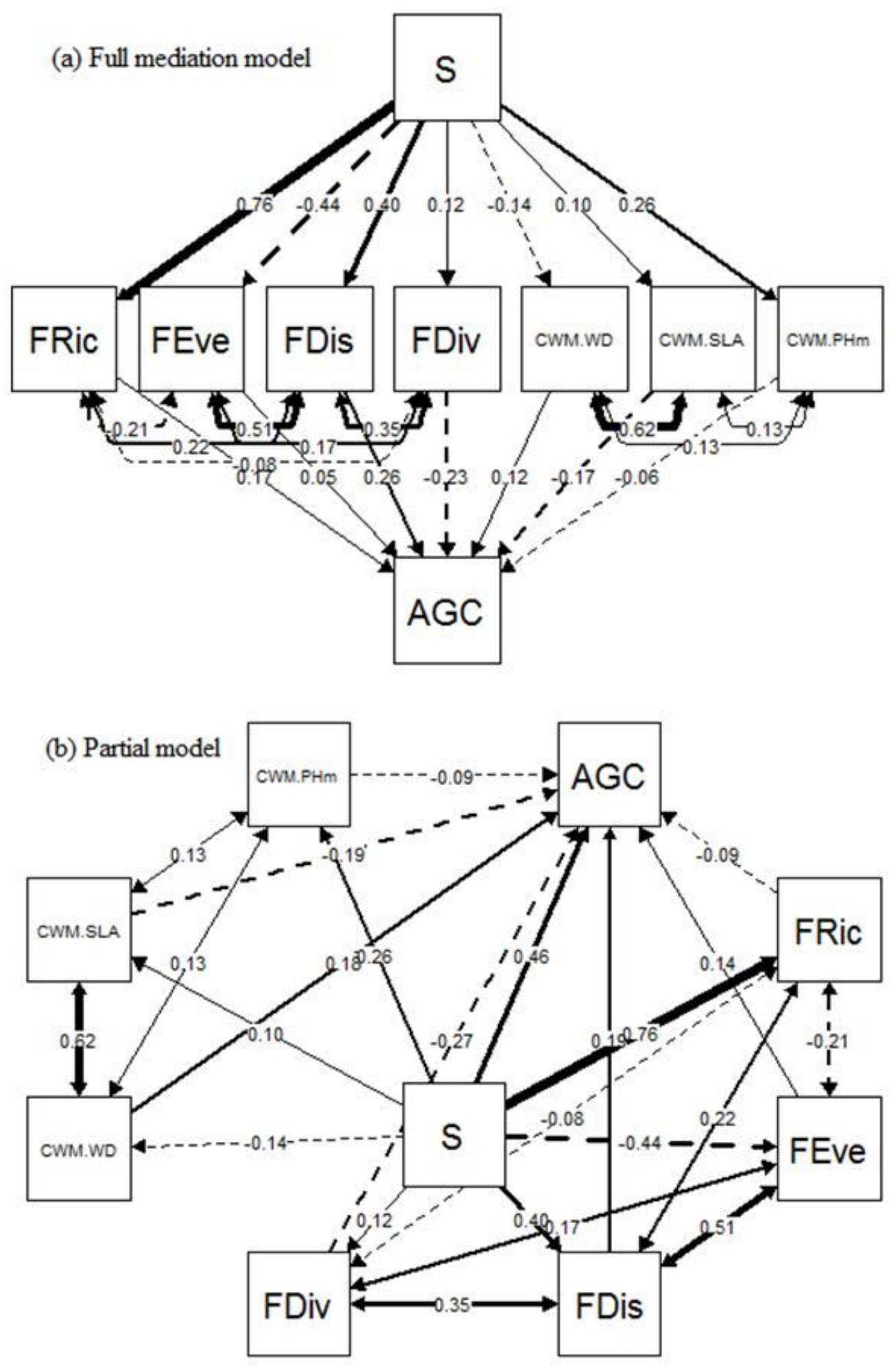

Figure 3

The best-fit structural equation models (SEMs) relating aboveground carbon to species richness, functional diversity, functional dominance. Legend: The figures are the standardized path coefficients. The single pointed arrows represent causal paths, whereas the double pointed arrows represent the residual correlations. The broken lines indicate the negative effects, whereas the dashed lines show 
positive effects; the significance of each path and model fit statistics are shown in presented in Table 1. CWM, PHm, SLA, and WD refer to table 1. 